\title{
A new actinic flux $4 \pi$-spectroradiometer: instrument design and application to clear sky and broken cloud conditions
}

\author{
E. Eckstein ${ }^{1}$, D. Perner ${ }^{1}$, Ch. Brühl ${ }^{1}$, and T. Trautmann ${ }^{2}$ \\ ${ }^{1}$ Max-Planck-Institut für Chemie, Mainz, Germany \\ ${ }^{2}$ Institut für Meteorologie, Universität Leipzig, Germany
}

Received: 23 August 2002 - Published in Atmos. Chem. Phys. Discuss.: 11 November 2002

Revised: 17 February 2003 - Accepted: 19 February 2003 - Published: 12 November 2003

\begin{abstract}
A new $4 \pi$-spectroradiometer was developed for measuring actinic flux especially under cloudy conditions based on a fixed grating imaging spectrograph and a CCDdetector leading to a simultaneous measurement of the spectrum. The new instrument incorporates a novel optical head with a $4 \pi$-field of view independent of angle of incidence. Comparisons with the actinic flux spectroradiometer of the Institute of Atmospheric Chemistry of Forschungszentrum Jülich showed a very good agreement within the limit of the uncertainties of the two instruments. Our spectroradiometer was applied to investigate the effects of broken clouds on the actinic flux and photolysis frequencies on the ground during the BERLIOZ campaign. Reductions as well as enhancements compared to the clear sky case were seen, both effects are larger in the UV-A than the UV-B spectral region. Furthermore the new instrument was used for simultaneous measurements in different altitudes on a tower to study the transmission and attenuation of actinic flux in low clouds. A correlation of attenuation with the simultaneously measured liquid water content of the cloud was found.
\end{abstract}

\section{Introduction}

Photodissociation processes driven by solar radiation at ultraviolet and visible wavelengths play a fundamental role in the chemistry of the atmosphere. As a consequence, precise determination of an in situ photolysis frequency is often as important as accurate measurement of the ambient mixing ratios of trace species. The simulation of photolysis frequencies is often used in atmospheric chemical models. For stable cloud-free and clean air, photolysis frequencies can be modeled quite well. Theoretical investigations of the photochemical relevant ("actinic") radiation (Madronich, 1987;

Correspondence to: E. Eckstein

(evieck@web.de) van Weele and Duynkerke, 1993; Ruggaber et al., 1994; Matthijsen et al., 1998; Reuder and Schwander, 1999; Liao et al., 1999) partially describe effects of clouds and aerosols but measurements are rare. For cloudy conditions radiation transfer models become quite complex, so that measurements for comparison purposes are greatly needed. The radiative parameter that determines the photolysis frequencies is the actinic flux $F(\lambda)$, defined as the incident radiance integrated over all solid angles:

$F(\lambda)=\int L(\lambda, \theta, \phi) \mathrm{d} \Omega$

where $L(\lambda, \theta, \phi)$ denotes the spectral photon radiance.

Knowing the wavelength dependent actinic flux $F(\lambda)$ and also the absorption coefficient $\sigma_{\mathrm{AB}}(\lambda)$ of a molecule $\mathrm{AB}$ and the quantum efficiency $\phi_{\mathrm{AB} \rightarrow \mathrm{A}+\mathrm{B}}(\lambda)$ of a certain reaction path $\mathrm{AB} \rightarrow \mathrm{A}+\mathrm{B}$, the photolysis frequency $J_{\mathrm{AB} \rightarrow \mathrm{A}+\mathrm{B}}$ can be calculated from

$J_{\mathrm{AB} \rightarrow \mathrm{A}+\mathrm{B}}=\int F(\lambda) \cdot \sigma_{\mathrm{AB}}(\lambda) \cdot \phi_{\mathrm{AB} \rightarrow \mathrm{A}+\mathrm{B}}(\lambda) \mathrm{d} \lambda$.

The techniques mostly used for measuring photolysis frequencies are filter radiometry (Junkermann et al., 1989; Brauers and Hofzumahaus, 1992; van Weele et al., 1995; Crawford et al., 1999) and chemical actinometry (Bahe et al., 1979; Dickerson et al., 1982; Parrish et al., 1983; Barai and Stedman, 1992; Shetter et al., 1992; Kelley et al., 1995). Chemical actinometers consist of a quartz glass tube containing a gas mixture which is exposed to solar radiation. The photolysis frequency can then be determined from the measured rate of change in the chemical gas composition. Filter radiometers measure the actinic flux integrated over a wavelength interval corresponding to a certain photolysis process, and are usually calibrated by comparison with chemical actinometers. Both techniques are suitable for only one particular process. Most often the photolysis frequency $J\left(\mathrm{NO}_{2}\right)$ and sometimes additionally $J\left(\mathrm{O}_{3} \rightarrow \mathrm{O}\left({ }^{1} \mathrm{D}\right)\right)$ are determined. For 
a complete description of the chemistry of the atmosphere many more photolysis frequencies are needed which can be derived easily based on the relatively new third method of actinic flux spectroradiometry. The principle of this method is to measure a relevant spectrum of the actinic flux and then calculate the photolysis frequency by Eq. (2). With this method photolysis frequencies of any molecule can be determined, as long as the species molecular parameters, i.e. the absorption coefficient and the quantum yield, are known and a suitable wavelength range is measured. As yet there are just two instruments described in the literature (Hofzumahaus et al., 1999; Shetter and Müller, 1999). Both of these use an entrance optic for a $2 \pi$-field of view and a double monochromator combined with a photomultiplier for detection of the actinic spectrum. This method is very good for measurements under stable conditions. However, for measurements under cloudy conditions, particularly where the extent of cloud cover is changeable, scanning the spectrum can lead to problems detecting different conditions for each wavelength interval: a distorted spectrum results. To avoid this problem we have developed a new actinic flux spectroradiometer using a single monochromator, which detects the whole spectrum from $300 \mathrm{~nm}$ to $660 \mathrm{~nm}$ simultaneously. The new instrument incorporates a novel optical head with a $4 \pi$ field of view independent of angle of incidence, which is especially necessary for measurements in clouds or above snow, when the intensity of the upward radiation can be of the same order as that of the downward radiation. Another interesting and novel feature of our instrument is the possibility of measuring at three points concurrently, for example at different altitudes on a tower. Another application of this feature could be, for example, the determination of the actinic flux at different heights in a forest.

The next section gives a detailed description of the instrument, including calibration procedures and spectrometer stray-light correction, followed by a section where the uncertainties are summarized. Section 4 presents a comparison of the measured actinic fluxes and photolysis frequencies with the double-monochromator-spectroradiometer of the Research Center Jülich for clear sky conditions and different solar zenith angles. Section 5 shows typical results obtained with the new instrument during the BERLIOZ campaign for conditions with broken clouds. In this section wavelength-dependent attenuations and enhancements of the actinic flux near the ground by broken clouds are demonstrated. In the last section before the conclusions an example for the application of the instrument for simultaneous measurements at different altitudes in a cloud on a tower, accompanied by measurements of cloud properties, is given.

\section{Details of the spectroradiometer}

For calculating photolysis frequencies the actinic flux over a $4 \pi$-field of view is required. Existing systems for measuring actinic flux use optical heads for a $2 \pi$-field of view and usually only measure the downward actinic flux. For groundbased measurements in the UV-B range $(300-320 \mathrm{~nm})$ the albedo is very small in most cases, but with increasing wavelength the albedo increases, so that the upward actinic flux may no longer be neglected. For measurements in clouds the upward component can be large. Existing actinic flux spectroradiometers detect a wavelength range from $280-420 \mathrm{~nm}$, but some atmospheric molecules are also photolysed in the visible wavelength range. In addition, for comparison with model calculations and to study the effects of clouds on the actinic flux, it is necessary to measure a large wavelength range very rapidly and simultaneously. Using a single grating monochromator and a CCD-camera, the spectroradiometer described in this paper fulfills these requirements over the wavelength range $300-660 \mathrm{~nm}$. The use of a CCD-camera for measuring spectral irradiance is also described by Harrison et al. (1999).

\subsection{Optical Collector}

The optical collector is based on the principle of multiple scattering in a teflon sphere. The diameter of the diffusing sphere is $30 \mathrm{~mm}$. Photons that enter the sphere lead to an isotropic radiation field, after a large number of scattering processes. The teflon sphere is screwed onto a small vertical metal tube (diameter $3 \mathrm{~mm}$ ) housing a quartz glass fiber. Through this fiber a small part of the diffuse radiation field is lead into the spectrograph described below. The fibers (BTO and Ceram Optics) used had a $600 \mu \mathrm{m}$ quartz core, a doped quartz cladding and an outer coating of polyamide. For protection against mechanical damage and weather abrasion the fibers were housed inside a flexible metal or PVC tube. The best position of the end of the fiber in the sphere was determined experimentally using a goniometer. The collector was positioned in the middle of the axis of a rotating arm on which a lamp is mounted. During the development of the instrument, measurements at different angle positions (steps of $\theta=5^{\circ}$ ) of the lamp were carried out, which gave the relative response function $Z_{\mathrm{p}}$ with respect to the position on top of the collector, just opposite the exit of the fiber. The best position found was approximately $3 \mathrm{~mm}$ below the center point of the sphere.

Figure 1 shows the relative response function $Z_{\mathrm{p}}$ of one of the collectors as a function of zenith angle $\theta . Z_{\mathrm{p}}$ was found to be independent of azimuth angle $\phi$, which is clearly shown in the figure. The deviation of $Z_{\mathrm{p}}$ from the ideal case of unity increases strongly for polar angles $|\theta|>165^{\circ}$ because of the shadow of the collector mounting. In the range $|\theta|<165^{\circ}$ the angle dependence for $660 \mathrm{~nm}$ varies less than $5 \%$ from the ideal case. For $320 \mathrm{~nm}$ on the other hand the discrepancy from the ideal value of one increases up to $15 \%$ for $|\theta|=120^{\circ}$. Thus there is an increasing dependence of $Z_{\mathrm{p}}$ on polar angle $\theta$ with decreasing wavelength. For correction of the angular and wavelength dependency of $Z_{\mathrm{p}}$ a procedure was used to 


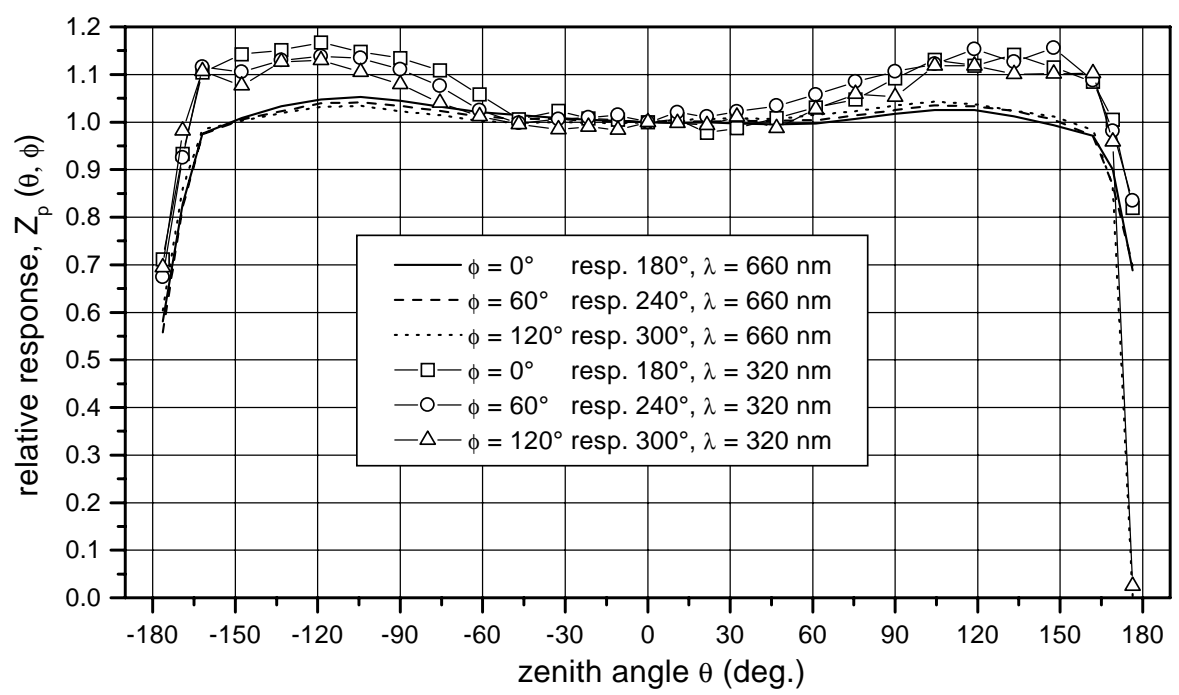

Fig. 1. Goniometrically determined relative response of the collector as a function of zenith angle $\theta$ at different azimuth angles. The negative zenith angles correspond to the opposite azimuth angle, for example, the values of negative zenith angles for azimuth $\Phi=0^{\circ}$ correspond to the azimuth angle $\Phi=180^{\circ}$.

transform the response function $Z_{p}(\lambda, \theta)$ into a correction function $Z_{H}\left(\lambda, \theta_{0}\right)$ which depends on wavelength and on the solar zenith angle, $\theta_{0}$. This transformation procedure was introduced by Hofzumahaus et al. (1999) for an optical head for a $2 \pi$-field of view, where $Z_{p}$ is a function of solar zenith angle but not of wavelength. For the new instrument this transformation was altered to allow for a $4 \pi$-field of view and a wavelength dependence of $Z_{\mathrm{p}}(\lambda, \theta)$. This procedure uses a simple model of atmospheric radiance $L(\lambda, \theta, \phi)$ near the ground and is described in detail in Sect. 2.5.2.

\subsection{The Monochromator}

The CP200, a $0.2 \mathrm{~m}$ fixed grating imaging spectrograph for array detectors, in combination with a CCD-camera, forms the basis of the optical instrumentation. It is small, portable and robust, with no moving parts in the basic instrument. Four different aberration-corrected concave holographic gratings can be used with this spectrograph. With the grating used $(200 \mathrm{~g} / \mathrm{mm})$, a spectrum from $190-820 \mathrm{~nm}$ with a length of $25 \mathrm{~mm}$ can be achieved. The width of the entrance slit can be varied from $50 \mu \mathrm{m}$ to $150 \mu \mathrm{m}$. Using the $50 \mu \mathrm{m}$ slit with a height of $8 \mathrm{~mm}$ a resolution between $1.8 \mathrm{~nm}$ and $2.8 \mathrm{~nm}$ can be achieved. With the CCD-camera the spectral range from $280 \mathrm{~nm}$ to $760 \mathrm{~nm}$ can be measured. Using the CCD-detector we are able to connect three quartz glass fibers to the spectrograph, so that three spectra from three optical collectors can be measured simultaneously. Three short fibers (length $12 \mathrm{~cm}$ ) are aligned one on top of the other at the entrance slit. The distance between two fibers was set at $0.9 \mathrm{~mm}$, to take maximum advantage of the height of the CCD-chip ( $4.6 \mathrm{~mm})$. Each of these short pieces is connected

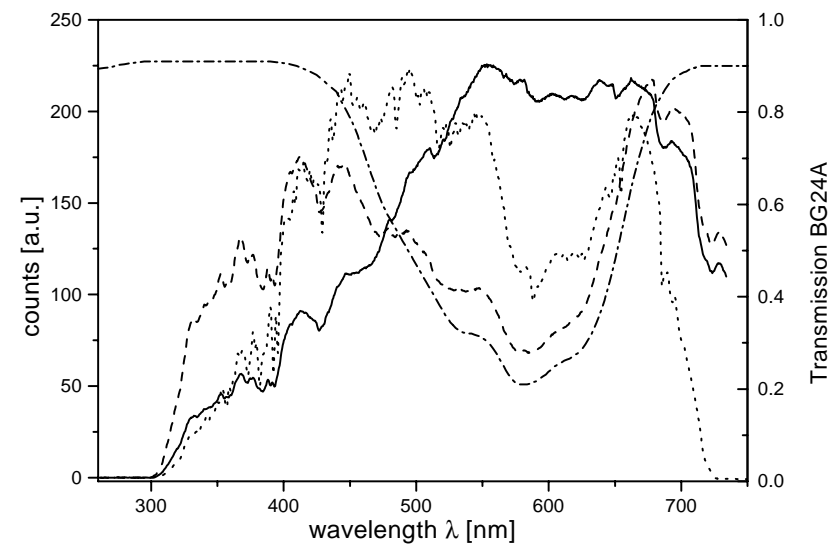

Fig. 2. Effects of the filter and the optical collector: (--) without either filter or optical collector, (- - ) with filter BG24A (Fa. Schott) but without optical collector; $(. \cdots)$ with filter BG24A, optical collector and baffle; $(-\cdot-\cdot-)$ transmission of the filter. The spectra are scaled to approximately the same maximum value in the visible ranges for better illustration of the relation of the UV with equal dynamic range of the CCD.

with a fiber of an optical collector using a FSMA-coupling. The length of the fibers of the collectors varies between 30 and $70 \mathrm{~m}$.

The intensity of the visible light in the solar spectrum is much higher than that in the UV range. To be able to measure both in the same spectrum with a sufficient signal intensity within the dynamical range of the $\mathrm{CCD}$, we equipped our spectrograph with a filter (BG24A, Schott, thickness $d=$ $0.5 \mathrm{~mm}$ ) to reduce the intensity of the visible light. The filter 


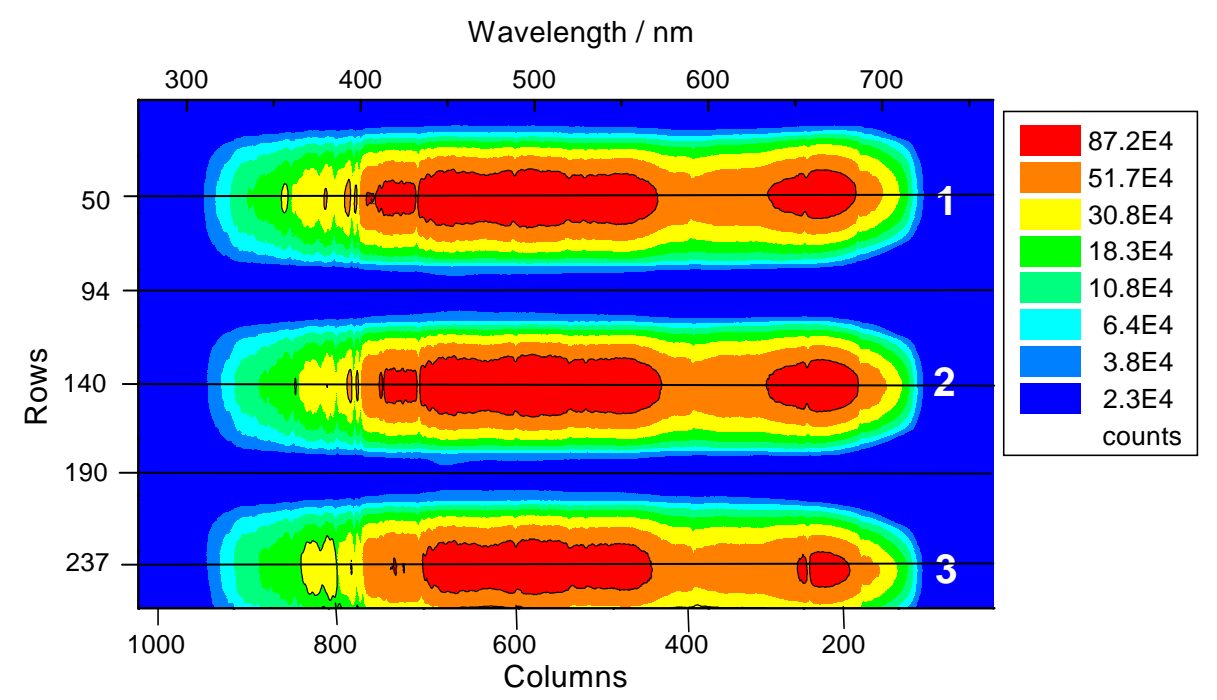

Fig. 3. Image of the CCD-chip when three optical collectors are connected. Rows number 94 und 190 are used as spectrometer stray-light spectra.

was mounted directly at the rear of the slit. Its maximum transmission is at $300 \mathrm{~nm}$. The largest reduction of the intensity of about $80 \%$ is at ca. $580 \mathrm{~nm}$. For longer wavelengths the transmission increases with increasing wavelength; Consequently, the light of wavelengths $\lambda>660 \mathrm{~nm}$ was dimmed mechanically. The performance of the filter and the optical collector are shown in Fig. 2. The solid line in the figure shows the spectrum obtained without either the filter or the collector. Using the filter (dashed line), a much higher signal is obtained in the UV-range, but with the same maximum intensity in the visible range. The spectrum with filter, collector and baffle (dotted line) shows a change of the spectral intensity distribution compared to the spectrum without collector and baffle.

The spectrograph is mounted together with the CCDcamera on a steelplate. To prevent wavelength shifts because of thermal expansion the spectrograph is housed inside a styrodur box which is temperature stabilized at $35^{\circ} \mathrm{C}$.

\subsection{The detector}

As mentioned previously the detector is a CCD-camera (EG $\& \mathrm{G})$. The camera uses a CCD-chip provided by Thomson CSF, Modell THX-7885M, which is a matrix of $1024 \times 256$ quadratic pixels of width $19 \mu \mathrm{m}$, resulting in a surface of $19.456 \times 4.864 \mathrm{~mm}^{2}$. It has a dynamical range of 18 bits. The exposure time is controlled with a shutter in front of the chip. For protection against mechanical damage, condensation of water vapor and chemical reactions, the CCD-chip is hermetically enclosed in a quartz glass container. A three-step peltier-cascade on its rear face transports excess heat to a liquid cooling system. Using water as coolant it is possible to achieve chip temperatures of $-64^{\circ} \mathrm{C}$, leading to a very small dark current. The quantum efficiency of ordinary CCD-chips drops to very low values for wavelength $<400 \mathrm{~nm}$. To improve the quantum efficiency, a luminescence layer was applied to the CCD surface in the production process. Thereby the quantum efficiency in the UV is about 0.2 compared to $0.2-0.37$ in the visible wavelength range.

\subsection{Data processing}

For measurement and data processing from the CCD output an extended version of the program "MFC" (Heismann, 1996) was used. This program offers the possibility to save the whole picture (intensity of every pixel), single rows or sums of several rows of the CCD.

Figure 3 shows the intensity distribution on the CCD-chip using three optical collectors simultaneously. The image of one collector covers about 50 rows. Ten rows in the range of the maximum intensity of these 50 rows are summed in a single spectrum to achieve the highest signal-to-noise-ratio. For three connected collectors three spectra are obtained; in addition, two single rows (row 94 and 190) are saved with each measurement. These two rows are located in the middle between the images of two collectors and are used for spectrometer stray-light correction (see Sect. 2.4.1). The spectra are recorded automatically; one measurement usually incorporates several scans to improve the signal-to-noise-ratio. The exposure time is calculated using the exposure time of the previous spectrum and the intensity in the wavelength range $500-600 \mathrm{~nm}$. The average signal value of this wavelength range is compared with a target value and determines the exposure time of the following spectrum. In most cases the number of scans is chosen in such a way that the total exposure time is between $30 \mathrm{~s}$ and $60 \mathrm{~s}$. At sunrise and sunset the total exposure time is increased to a maximum of $300 \mathrm{~s}$ or $900 \mathrm{~s}$. During daylight hours exposure times of $3 \mathrm{~s}$ are 
Table 1. Maximum Errors of the measured actinic fluxes

\begin{tabular}{|c|c|c|c|c|c|c|c|c|c|}
\hline Source of uncertainty & $\lambda$ & $>$ & $330 \mathrm{~nm}$ & $\lambda$ & $<$ & $330 \mathrm{~nm}$ & $\lambda$ & $<$ & $310 \mathrm{~nm}$ \\
\hline Irradiance standard uncertainty & & \pm & $4 \%$ & & \pm & $4 \%$ & & \pm & $4 \%$ \\
\hline Error of $\Delta z$ & $<$ & \pm & $1 \%$ & $<$ & \pm & $1 \%$ & $<$ & \pm & $1 \%$ \\
\hline $\begin{array}{l}\text { Accuracy of wavelength } \\
\text { calibration }( \pm 0.15 \mathrm{~nm})\end{array}$ & $<$ & \pm & $1 \%$ & & \pm & $3 \%$ & & \pm & $5 \%$ \\
\hline Reproducibility of fiber coupling & $<$ & \pm & $0.5 \%$ & $<$ & \pm & $0.5 \%$ & $<$ & \pm & $0.5 \%$ \\
\hline $\begin{array}{l}\text { Uncertainty of straylight correction } \\
\text { Uncertainty of correction of }\end{array}$ & $<$ & \pm & $1 \%$ & $<$ & \pm & $2 \%$ & $<$ & \pm & $10 \%$ \\
\hline angle dependence & & \pm & $2 \%$ & & \pm & $5 \%$ & & \pm & $10 \%$ \\
\hline Total uncertainty & & \pm & $5 \%$ & & \pm & $7 \%$ & & \pm & $15 \%$ \\
\hline
\end{tabular}

possible for $\theta_{0}<45^{\circ}$, based on just one scan. However, several scans are usually combined to give a better signal-tonoise-ratio.

The electronic offset and dark current were determined by leaving the shutter closed for a range of exposure times. The offset was nearly the same in every pixel, with an average value of $1246 \pm 4$ counts per pixel. The additional dark current originating from thermal exitation was determined to be $0.09 \pm 0.002$ counts $\mathrm{s}^{-1}$.

\subsubsection{Spectrometer stray-light}

This section describes the analysis done to characterize the spectrometer stray-light, which has to be corrected for especially in the UV wavelength range because of the small intensities involved. If we imagine the stray-light to be distributed homogeneously over the CCD-chip then stray-light should be a constant value for every pixel depending only on the incoming light intensity. Unfortunately, this was not the case. In the area of the image of each collector two different contributions of stray light are observed, first, stray light from the collector itself; second, from the other two collectors. From measurements with different edge filters and connected single collectors we found that rows 94 and 190 between the images of the collectors describe the existing stray-light distribution reasonably well (Eckstein, 2001).

The stray light was accounted for in the following way. The stray-light spectrum was scaled in the wavelength range 270-290 $\mathrm{nm}$ to the average value of the spectrum of the collector in the same range, and then substracted. For the collector which was connected on the top (SRM-1) row 94 was used as the stray-light spectrum, for the collector connected in the middle (SRM-2) the average of row 94 and 190 was used, and for the collector connected on the bottom (SRM3) row 190 was used as stray-light spectrum. This correction lead to an overestimation of the straylight in the wavelength range $\lambda>700 \mathrm{~nm}$, but this range was not used in further data processing. The proportion of stray light in the total signal is less than $1 \%$ in the wavelength range $\lambda>330 \mathrm{~nm}$, but increases strongly for wavelengths $\lambda<330 \mathrm{~nm}$. The straylight correction is therefore very sensitive in this region. The stray-light correction described gives uncertainties in the actinic flux values as specified in Table 1. The stray-light uncertainty and, as a consequence the uncertainty in the correction of the angle dependence of the collector are the largest error sources for wavelengths $\lambda<310 \mathrm{~nm}$.

\subsection{Calibration}

\subsubsection{Wavelength calibration}

For wavelength calibration two different low-pressure halogen lamps were used. For the wavelength range $\lambda<550 \mathrm{~nm}$ spectra of a Hg-lamp and for the range $\lambda>550 \mathrm{~nm}$ spectra of an Ar-lamp (Type 'Pen Ray, LOT) were measured. Eight emission lines (Hg-lines: 296.73, 302.15, 312.57, 365.02, 404.66, 435.84, 546,07 nm; Ar-line: $696.54 \mathrm{~nm}$ ) were assigned to their measured peak position. The pairs of points determined in this way were fitted to a third-order polynomial function for the total measured wavelength range. The distances of the pixels arising from this procedure were nearly equidistant in the range between 0.47 and $0.49 \mathrm{~nm}$. For constant and stable temperature conditions the reproducibility of the emission-lines was $\pm 0.03 \mathrm{~nm}$. Wavelength shifts arose due to temperature fluctuations during field measurements. However, these could be corrected by correlating the Fraunhofer structure of the spectra to a reference solar spectrum measured at the same time as the wavelength calibration was performed. The resulting uncertainty in the wavelength assignment, determined from several wavelength calibration measurements during one year, was $\pm 0.15 \mathrm{~nm}$. Comparison of the positions of the measured Fraunhofer lines with a high resolution extraterrestrial solar spectrum of Van Hoosier (ftp://susim.nrl.navy.mil/pub/atlas3), convoluted with our instrumental response function, showed very good agreement, with a deviation of less than $\pm 0.1 \mathrm{~nm}$. 


\subsubsection{Actinic flux calibration}

The concept of the actinic flux calibration is similar to the method presented by Hofzumahaus et al. (1999) and is therefore discussed here only in brief. In theory the spectral response function $D(\lambda, \theta, \phi)$ should be determined for every steradian element $d \Omega=\sin \theta d \theta d \phi$. In the atmosphere, the relation between the measured signal $I(\lambda)$ and the collected radiation is given by

$$
\begin{aligned}
\mathrm{d} I(\lambda) & =D(\lambda, \theta, \phi) \cdot L(\lambda, \theta, \phi) d \Omega \\
& =D_{0}(\lambda) \cdot Z_{p}(\lambda, \theta, \phi) \cdot L(\lambda, \theta, \phi) d \Omega .
\end{aligned}
$$

$D_{0}(\lambda)$ is the response function for $\theta=0^{\circ}$ and $Z_{p}(\lambda, \theta, \phi)$ describes the relative sensitivity of the collector with respect to the direction $\theta=\phi=0^{\circ}$, for which $Z_{p}=1$. In Sect. 2.1 we described the dependence of $Z_{\mathrm{p}}$ on wavelength and polar angle $\theta$. During field measurements the collector integrates the radiation over all angles of incidence, so that

$$
I=D_{0}(\lambda) \int_{4 \pi s r} Z_{p}(\lambda, \theta) L(\lambda, \theta, \phi) d \Omega
$$

The correction function $Z_{H}\left(\lambda, \theta_{0}\right)$ is introduced in the following way:

$$
\begin{aligned}
I(\lambda) & =D_{0}(\lambda) Z_{H}\left(\lambda, \theta_{0}\right) F(\lambda, 4 \pi s r), \\
Z_{H}\left(\lambda, \theta_{0}\right) & =\frac{1}{F(\lambda, 4 \pi s r)} \int_{4 \pi s r} Z_{p}(\lambda, \theta) L(\lambda, \theta, \phi) d \Omega
\end{aligned}
$$

Using Eqs. (13)-(16) of Hofzumahaus et al. (1999) and the proportions of the direct $F_{0}$, the downward $F \downarrow$ and the upward $F \uparrow$ diffuse flux to the total actinic flux $F(4 \pi s r)$,

$$
\begin{aligned}
& \alpha=\frac{F_{0}}{F_{0}+F \downarrow+F \uparrow}=\frac{F_{0}}{F(4 \pi s r)}, \\
& \beta=\frac{F \uparrow}{F_{0}+F \downarrow+F \uparrow}=\frac{F \uparrow}{F(4 \pi s r)}, \\
& \gamma=\frac{F \downarrow}{F_{0}+F \downarrow+F \uparrow}=\frac{F \downarrow}{F(4 \pi s r)}
\end{aligned}
$$

we obtain

$Z_{H}=\alpha Z_{p}+\frac{\gamma}{2 \pi} \int_{U H} Z_{p} d \Omega+\frac{\beta}{2 \pi} \int_{L H} Z_{p} d \Omega$

where UH means upper hemisphere and LH means lower hemisphere. $Z_{H}, Z_{p}, \alpha, \beta$ and $\gamma$ are all dependent on $\lambda$ and $\theta_{0} . \quad \alpha, \beta$ and $\gamma$ were determined from model simulation using a $\delta$-4-stream method (Früh et al., 2000). A standard ozone profile of midlatitude summer (McClatchey et al., 1971) was used in the calculations, which was scaled in each vertical layer to yield an ozone column of $300 \mathrm{DU}$ in total. The albedo was determined from measurements at a height of $100 \mathrm{~m}$ on the Charité building in Berlin, and was found to be between about $1 \%$ at $300 \mathrm{~nm}$ up to $18 \%$ at $660 \mathrm{~nm}$. Aerosol effects were neglected. Model simulations were carried out for solar zenith angles in the range $0-80^{\circ}$ in steps of $5^{\circ}$. With these assumptions $Z_{H}(\lambda)$ was calculated in steps of $\delta \theta_{0}=5^{\circ}$, which was then used for the following parameterisation:

$Z_{H}\left(\lambda, \theta_{0}\right)=\sum_{n=0}^{n=5} A_{n}(\lambda) \cdot \theta_{0}^{n}$.

The assumption of isotropic diffuse sky radiation lead to deviations in $Z_{H}$ of less than $\pm 2 \%$ when compared with a nonisotropic distribution of radiation (Hofzumahaus et al., 1999). For $\theta_{0}>90^{\circ}$ and total cloud cover $\alpha$ is zero. In these cases $Z_{H}$ is independent of $\theta_{0}$, and the resulting error in $Z_{H}$ is smaller than $\pm 3 \%$.

Knowing the correction function $Z_{H}$ the actinic flux is determined from the measured signal $I(\lambda)$ from

$F(\lambda)=\frac{I(\lambda)}{Z_{H}\left(\lambda, \theta_{0}\right) \cdot D_{0}(\lambda)}$.

It follows, therefore, that an absolute calibration is still required, namely the system response function $D_{0}(\lambda)$ at $\theta=0^{\circ}$. Because of the equivalence of the actinic flux and the irradiance at $\theta=0^{\circ}, D_{0}$ can be determined with an irradiance standard. However, the problem arises of deciding what distance to choose between the collector and the standard, since the collector is not a plane but rather a sphere, without a unique basing point. Considering different planes of the collector perpendicular to the optical axis (sphere-standard), the surface elements have differing distances to the standard and therefore receive different irradiance intensities. A virtual plane must therefore be found, which can be used to adjust the distance to the irradiance standard. After Hofzumahaus et al. (1999) we make use of the fact that the irradiance is proportional to the inverse square of the distance. Therefore, measurements were carried out in a dark laboratory at varying distances from the top of the collector to a quartz halogen lamp. The resulting intensities $I^{-1 / 2}$ were proportional to the distance in the range $10-90 \mathrm{~cm}$ for all wavelength as expected. The $\mathrm{x}$-value at which the extrapolated linear fit curves of $I^{-1 / 2}$, plottet against the distance, intersect the xaxis, is the distance $|\Delta z|$ of the virtual plane which behaves like a plane irradiance receiver optic. For our collectors the mean values for $|\Delta z|$ were $32 \pm 2 \mathrm{~mm}$ (SRM-1), $30 \pm 2 \mathrm{~mm}$ (SRM-2) and 30 $\pm 3 \mathrm{~mm}$ (SRM-3).

The absolute calibration was carried out in a laboratory of the Institute of Atmospheric Chemistry of the Forschungszentrum Jülich (Germany). There a calibrated $1000 \mathrm{~W}$ irradiance standard (Fa. Gigahertz Optik) was operated at a constant current, as specified in the lamp certificate. The fluctuations of the current were within $\pm 15 \mathrm{ppm}$ of the certified value (for details see Hofzumahaus et al., 1999). The distance between the virtual plane of our detector and the lamp was $700 \mathrm{~mm}$, as prescribed by the lamp certificate. 
The observed response function, $D_{0}$, of one of the collectors is shown in Fig. 4.

Because of decreasing transmission of the fiber and the collector, $D\left(\lambda, \theta_{0}\right)$ also decreases for $\lambda<400 \mathrm{~nm}$ with smaller wavelength. The response functions of the other collectors were found to be similar. However because of transmission inefficiencies the response function becomes smaller with increasing length of the fiber.

\section{Uncertainties}

The sources of uncertainty in the actinic flux measurements are listed in Table 1. The two largest error terms are the uncertainty of the irradiance standard and the spectrometer stray-light correction. From a comparison of various irradiance standards Hofzumahaus et al. (1999) estimated an uncertainty of $\pm 4 \%$. The spectrometer stray-light correction error has a strong spectral dependence, and it is relatively greatest at short wavelengths, where signal intensity is lowest. The uncertainty of stray-light correction can reach up to $10 \%$ for $\lambda<305 \mathrm{~nm}$ for midday values on clear-sky days. For wavelengths $\lambda<300 \mathrm{~nm}$ the signal intensity diminishes, so that the signal-to-noise ratio becomes unity and the detection limit of the instrument is reached. With increasing solar zenith angle the detection limit shifts to longer wavelength, which can be seen in Fig. 5. The error in $\Delta z$, the position of the virtual plane which is used for calibration, is $\pm 5 \mathrm{~mm}$, which leads to an uncertainty in the actinic flux of less than $1 \%$, when measuring at a distance of $700 \mathrm{~mm}$ to the irradiance standard. The error of the wavelength calibration has a strong spectral dependence in the actinic flux. This effect was investigated by shifting a spectrum for $0.15 \mathrm{~nm}$ and then calculating the ratio with the original spectrum. This procedure was carried out for several spectra and then the standard deviation was determined. In the range of the UV-B cutoff the error of $0.15 \mathrm{~nm}$ leads to an uncertainty in the actinic flux of $3 \%$ to $5 \%$. For $\lambda>330 \mathrm{~nm}$, on the other hand, the averaged uncertainty is only about $1 \%$. The uncertainty in the correction of the angle dependence owing to the idealised assumptions was estimated to $\pm 2 \%$ for wavelengths $\lambda>330 \mathrm{~nm}$ according to Hofzumahaus et al. (1999). For decreasing wavelength the uncertainty in this correction increases because of the rising error in the spectrometer stray-light correction. For cloudy conditions, when no direct light reaches the collector, the uncertainty in the correction of the angle dependence can reach $3 \%$ for $\lambda>330 \mathrm{~nm}$. The long quartz fibers of the collectors are connected with short fibers which are installed at the slit of the spectrograph. The uncertainty in the actinic flux after disconnection and reconnection of the fibers, was determined to be less than $0.5 \%$. The errors listed in table 1 yield a total uncertainty of $5 \%$ for $\lambda>330 \mathrm{~nm}, 7 \%$ for $310 \mathrm{~nm}<\lambda<330 \mathrm{~nm}$ and $15 \%$ for $\lambda<310 \mathrm{~nm}$. The error is not constant within the given wavelength limits, but rather continuously increases from $330 \mathrm{~nm}$ to lower wavelengths; the

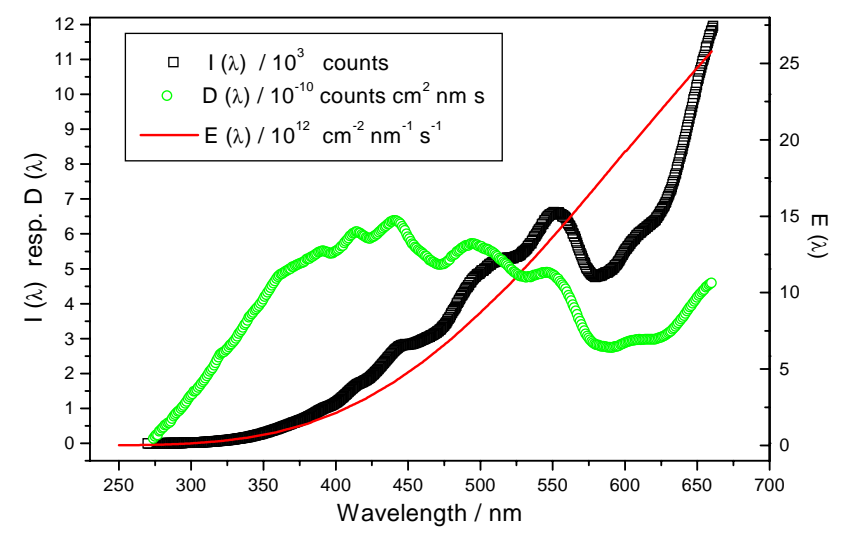

Fig. 4. Comparison of the irradiance $E(\lambda)$ produced by the $1000 \mathrm{~W}$ standard in a distance of $700 \mathrm{~mm}$, the signal intensity $I(\lambda)$ and the spectral response function $D\left(\lambda, \theta_{0}\right)$ of one collector (SRM-3).

given uncertainties should be taken as average errors in the given spectral ranges.

The uncertainties in the photolysis frequencies, calculated with the measured actinic flux spectra are estimated to $\pm 5 \%$ for processes which take place at wavelength $\lambda>330 \mathrm{~nm}$, as for example $J\left(\mathrm{NO}_{2}\right)$. Because of the integration over a larger wavelength region for calculating photolysis frequencies the uncertainty for processes which occur in the spectral range $<330 \mathrm{~nm}$ is estimated to be $\pm 10 \%$. Of course the absorption coefficients and quantum yields which are used to calculate the photolysis frequency also have associated errors, which contribute to the total error of the photolysis frequencies. Hofzumahaus et al. (1999) estimated the uncertainty of the quantum yields to be about $\pm 10 \%$, whereas the accuracy of the absorption coefficients may be as high as $3 \%$ in some cases.

\section{Results for clear-sky conditions and comparison with the Jülich instrument}

\subsection{Spectral actinic flux}

To check the accuracy of the SRM, comparison measurements with the spectroradiometer of the Institute of Atmospheric Chemistry of the Forschungszentrum Jülich (SRJ, Hofzumahaus et al., 1999) were carried out on the roof of the Institute in Jülich (Germany; $51.00^{\circ} \mathrm{N}, 6.50^{\circ} \mathrm{E}$ ) during November 1998 and May 1999. The SRJ is a scanning spectroradiometer for the wavelength range $280-420 \mathrm{~nm}$ which uses a double monochromator. It measures the actinic flux of the upper hemisphere $(2 \pi s r)$. For measuring just a $2 \pi$ field of view, like the SRJ, we placed a black plane just beyond the collectors of the SRM. Typical clear sky spectra measured with one collector of our instrument (SRM-2) and with the SRJ on 27 May 1999, are shown for two solar zenith 

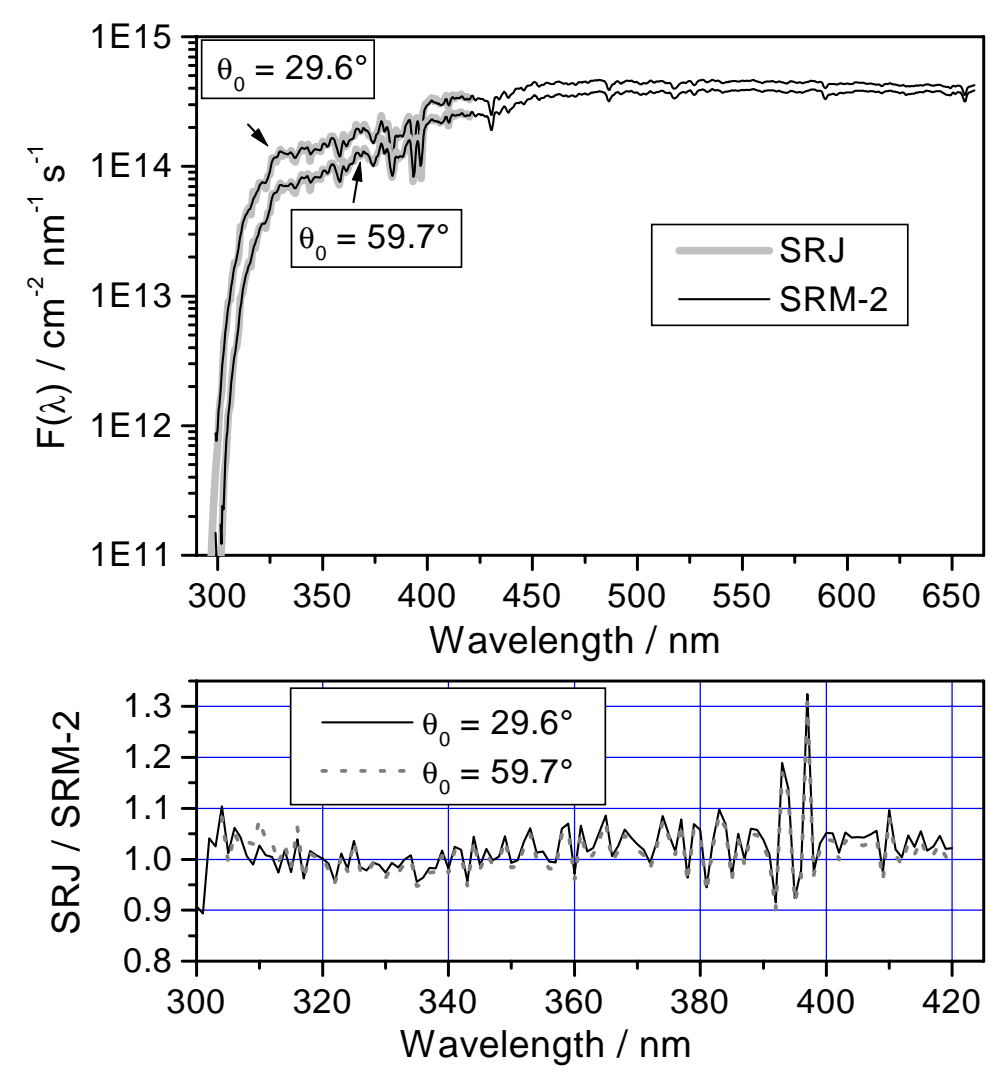

Fig. 5. Upper panel: Spectral actinic flux measured with one of the three collectors of the SRM (SRM-2) and with the actinic flux spectroradiometer of the Institute of Atmospheric Chemistry of the Forschungszentrum Jülich (SRJ) simultaneously on 27 May 1999 on the roof of the Institute in Jülich at two different solar zenith angles. Lower panel: Ratios of the shown spectra of the SRJ and the SRM-2. The upper wavelength limit is restricted to $420 \mathrm{~nm}$ because of the range of measurement of the SRJ.

angles in Fig. 5. The spectra show clearly the shift of the sharp cutoff in the UV-B range to higher wavelengths with increasing solar zenith angle. The two instruments show good agreement. For actinic flux values lower than about $10^{11}$ photons $\mathrm{cm}^{-2} \mathrm{~s}^{-1} \mathrm{~nm}^{-1}$ the signal of the SRM is equal to the noise, so this value represents the instrument's detection limit. The ratios of the spectra shown in Fig. 5 (upper panel) are illustrated in Fig. 5 (lower panel). The ratios generally vary in the range of $\pm 10 \%$ around unity, which is in the range of the uncertainty of the two instruments. The only exception is in the wavelength range $390-400 \mathrm{~nm}$, where the strong solar Ca Fraunhofer lines were measured at different resolutions by the two instruments, yield larger deviations.

To demonstrate the good agreement of the three collectors with each other ratios of spectra measured on 3 November 1998 are illustrated in Fig. 6 . For wavelengths $\lambda>330 \mathrm{~nm}$ the ratios are in the range of $1.00 \pm 0.05$, except for SRM$1 /$ SRM-2, which is in the range of $1.00 \pm 0.08$. Low intensities yield increasing uncertainties in the wavelength range $\lambda<330 \mathrm{~nm}$ which lead to increasing deviations from 1.00 of the spectral ratios. However, the solar zenith angles shown here are rather large. At smaller solar zenith angles the UV-B cutoff shifts to smaller wavelengths and therefore the deviations of the spectra also start to increase at smaller wavelengths.

Large discrepancies also appear at about $\lambda=393 \mathrm{~nm}$ and $\lambda=397 \mathrm{~nm}$ in the ratios SRM-1/SRM-2 and SRM-2/SRM-3, in the range of the strong solar Ca Fraunhofer lines. These deviations clearly do not occur in the ratio SRM-1/SRM-3. The reason is that the resolutions of SRM- 1 and SRM- 3 are quite similar, whereas the resolution of SRM-2 is higher. This difference is caused by the imaging properties of the spectrograph, which are best in the middle of the grating.

\subsection{Photolysis frequencies}

Using literature data for the molecular absorption coefficient and the quantum yield for a given photolysis reaction, the photolysis frequency can be determined from the measured spectra of actinic flux from Eq. (2). For example the photolysis frequencies of ozone

$$
\mathrm{O}_{3}+h v \rightarrow \mathrm{O}\left({ }^{1} \mathrm{D}\right)+\mathrm{O}_{2} \quad\left(J\left(\mathrm{O}\left({ }^{1} \mathrm{D}\right)\right)\right)
$$




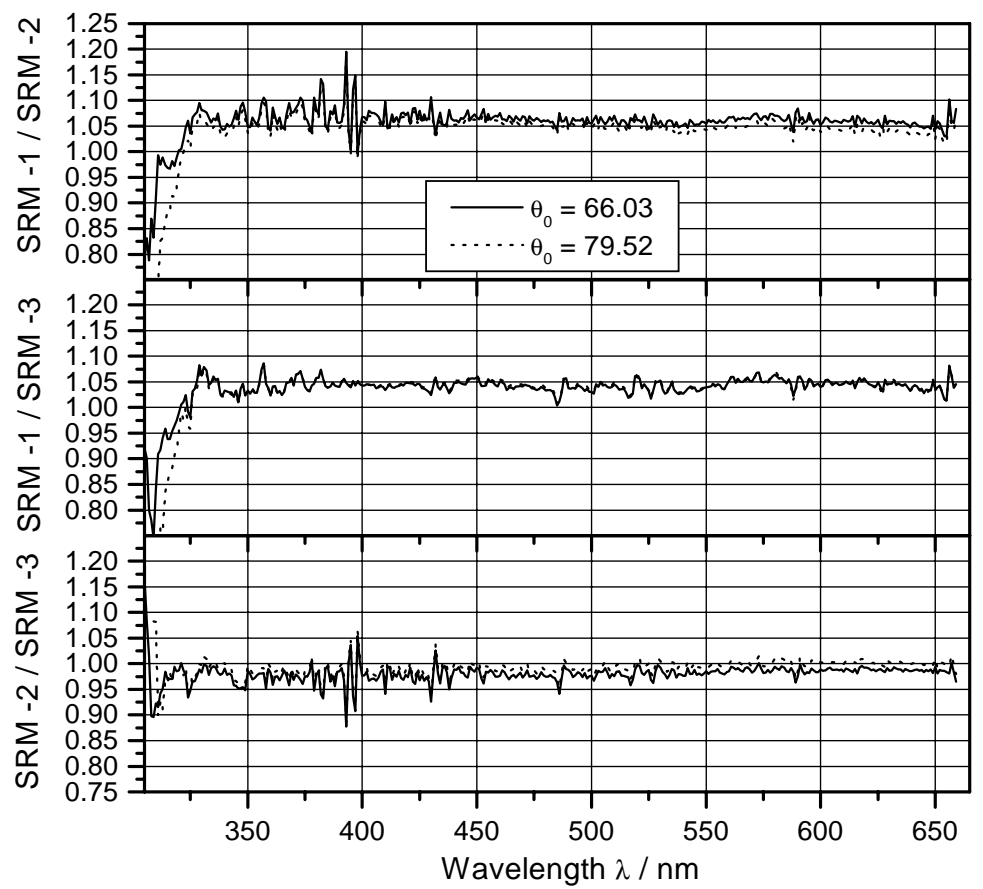

Fig. 6. Ratios of spectra of the three collectors SRM-1, SRM-2, SRM-3 measured on 3 November 1998 at two different solar zenith angles.
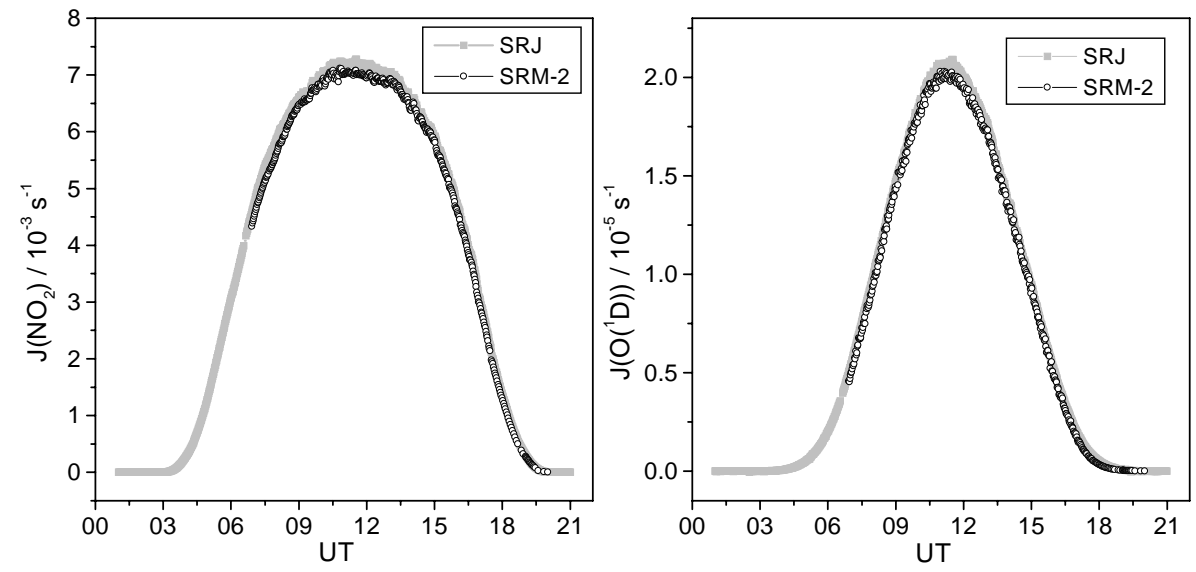

Fig. 7. Diurnal profiles of the photolysis frequencies $J\left(\mathrm{O}\left({ }^{1} \mathrm{D}\right)\right)$ and $J\left(\mathrm{NO}_{2}\right)$ measured with one collector of the SRM (SRM-2) and the SRJ on 27 May 1999 on the roof of the Institute of Atmospheric Chemistry (ICG3) (Jülich, Germany).

and nitrogen dioxide

$\mathrm{NO}_{2}+h v \rightarrow \mathrm{NO}+\mathrm{O} \quad\left(J\left(\mathrm{NO}_{2}\right)\right)$

are shown in Fig. 7, as measured on 27 May 1999 on the roof of the Institute of Atmospheric Chemistry (ICG3) (Jülich, Germany) with the SRM-2 and the SRJ. They were calculated with literature data of DeMore et al. (1997) $(\sigma)$ and Talukdar et al. (1998) $(\Phi)$ for $J\left(\mathrm{O}\left({ }^{1} \mathrm{D}\right)\right)$ and Merienne et al. (1995) $(\sigma)$ and DeMore et al. (1997) $(\Phi)$ for $J\left(\mathrm{NO}_{2}\right)$.

Figure 7 shows that the diurnal profiles of $J\left(\mathrm{O}\left({ }^{1} \mathrm{D}\right)\right)$ and $J\left(\mathrm{NO}_{2}\right)$ differ in width, because of the different spectral ranges which contribute to the two photolysis frequen- cies. The photolysis of $\mathrm{NO}_{2}$ takes place in the range $300 \mathrm{~nm}<\lambda<420 \mathrm{~nm}$, with the main contribution coming from the wavelength region $350<\lambda<420 \mathrm{~nm}$. Photolysis $\mathrm{O}_{3}$ to $\mathrm{O}\left({ }^{1} \mathrm{D}\right)$, on the other hand, occurs in the range $295<\lambda<330 \mathrm{~nm}$.

The diurnal profiles of the two instruments show good agreement for both photolysis frequencies. To quantify the level of agreement of the SRM and SRJ the photolysis frequencies $J\left(\mathrm{O}\left({ }^{1} \mathrm{D}\right)\right)$ and $J\left(\mathrm{NO}_{2}\right)$ measured in the period 21 May 1999 to 28 May 1999 are shown in a correlation plot (Fig. 8), where SRJ is plotted on the abscissa. Also shown in Fig. 8 are linear best-fit lines forced through the origin. 

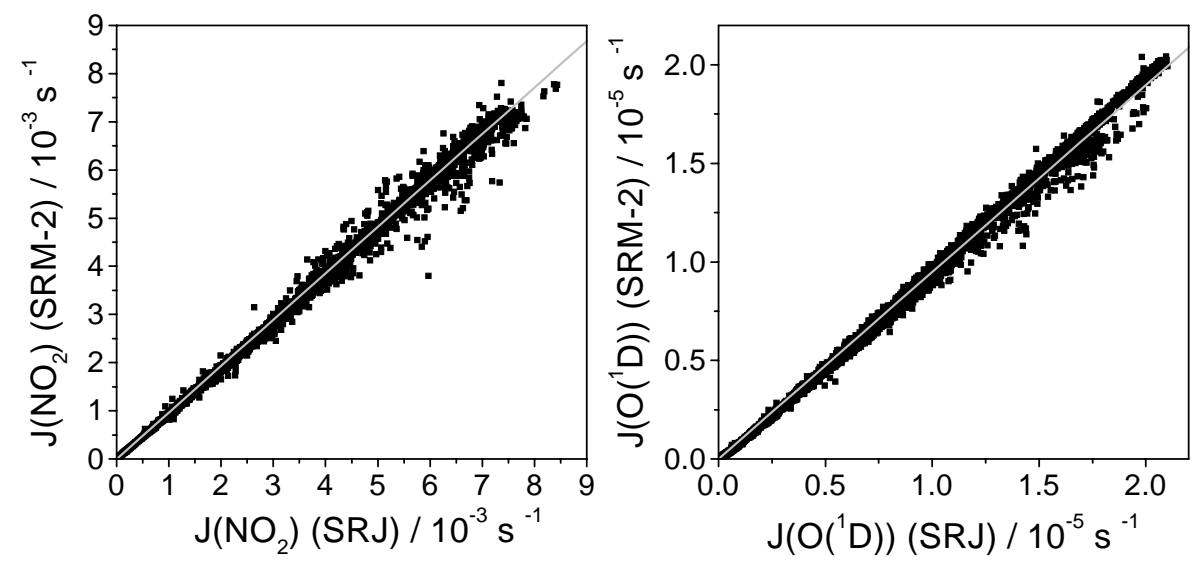

Fig. 8. Correlation plot of $J\left(\mathrm{O}\left({ }^{1} \mathrm{D}\right)\right)$ and $J\left(\mathrm{NO}_{2}\right)$ of the SRM (SRM-2) against SRJ for all measured data in the period 21 May $1999-28$ May 1999.

The two instruments show a very good linear correlation with correlation coefficients of 0.999 for $J\left(\mathrm{O}\left({ }^{1} \mathrm{D}\right)\right)$ and 0.998 for $J\left(\mathrm{NO}_{2}\right)$, although values taken during cloudy conditions are included. The slope of the linear fit is a measure of the deviation of the two instruments. Therefore, the values of the slope of 0.949 for $J\left(\mathrm{O}\left({ }^{1} \mathrm{D}\right)\right)$ and 0.964 for $J\left(\mathrm{NO}_{2}\right)$ show a very good agreement of the two instruments in the range of their uncertainties.

Figure 9 shows the normalized relative departure of the correlations shown in Fig. 8 as a function of solar zenith angle. For $J\left(\mathrm{NO}_{2}\right)$ we get small scatter around zero with a small standard deviation of \pm 0.038 for the whole range of zenith angles. The relative departure of $J\left(\mathrm{O}\left({ }^{1} \mathrm{D}\right)\right)$ shows small scatter around zero up to solar zenith angles of about $70^{\circ}$. For larger solar zenith angles there seems to be a systematic deviation to negative values. The detection limit of the SRM is reached at higher wavelength than the detection limit of the SRJ. Therefore, for large solar zenith angles the very small wavelength in the range between 295 and $310 \mathrm{~nm}$ do not contribute to $J\left(\mathrm{O}\left({ }^{1} \mathrm{D}\right)\right)$ of the SRM, but contribute to $J\left(\mathrm{O}\left({ }^{1} \mathrm{D}\right)\right)$ of the SRJ, leading to smaller values of $J\left(\mathrm{O}\left({ }^{1} \mathrm{D}\right)\right)$ for the SRM compared to the SRJ. However, the standard deviation of the relative departure of $J\left(\mathrm{O}\left({ }^{1} \mathrm{D}\right)\right)$ is 0.074 in the solar zenith angle range of $28-80^{\circ}$, which shows a very good agreement of the two instruments for the photolysis frequency $J\left(O\left({ }^{1} \mathrm{D}\right)\right)$, and well within their uncertainty range.

\section{Results for broken clouds, BERLIOZ}

During the field campaign BERLIOZ (BERLin OZone experiment) from 12 July to 10 August 1998, we investigated the effects of broken cloud conditions on the actinic flux at ground level. The SRM was installed on the roof of the Charité building in the city of Berlin (Germany; $52.53^{\circ} \mathrm{N}$, $\left.13.38^{\circ} \mathrm{E}\right)$. Figure 10 shows diurnal profiles of the photolysis frequencies $J\left(\mathrm{O}\left({ }^{1} \mathrm{D}\right)\right)$ and $J\left(\mathrm{NO}_{2}\right)$ measured on $9 \mathrm{Au}-$ gust 1998. An interesting point is the different effect of clouds, which were present in the morning between 05:00 and 09:00 UT, for the two photolysis processes. The reduction and enhancement of photolysis is much more pronounced in $J\left(\mathrm{NO}_{2}\right)$ than in $J\left(\mathrm{O}\left({ }^{1} \mathrm{D}\right)\right)$ during that time, indicating a wavelength-dependent effect of broken clouds. Similar observations were noted by Junkermann et al. (1989). Wavelength-dependent effects of clouds on the irradiance were also described by Frederick and Erlick (1997) and Kylling et al. (1997).

To investigate if the effects of clouds, especially broken clouds, are wavelength-dependent we compared spectra measured during partial cloud cover with clear-sky spectra. Clear-sky spectra were not taken from one single day, but were averaged for different aerosol conditions; all clear-sky spectra measured during BERLIOZ for a given solar zenith angle in the range of $\pm 0.25^{\circ}$ were averaged. Exemplary, the ratios of three spectra measured during partial cloud conditions on 3 August 1998 with the corresponding clear-sky spectra are shown in Fig. 11. The times of measurement are marked in the photolysis frequency $J\left(\mathrm{NO}_{2}\right)$ in the lower panel (full line). The dashed line in the lower panel shows a parameterization of $J\left(\mathrm{NO}_{2}\right)$ for clear sky conditions. One spectrum is taken from a local minimum of $J\left(\mathrm{NO}_{2}\right)$, that is in the shadow of a cloud; the second spectrum is at a point where $J\left(\mathrm{NO}_{2}\right)$ is very close to the clear-sky value; and in the third spectrum $J\left(\mathrm{NO}_{2}\right)$ is enhanced compared to clearsky conditions, that is, in a cloud gap, where direct radiation reaches the instrument. The ratios of the cloudy spectra to the clear-sky spectra of the minimum and the enhancement cases show a significant wavelength dependence. In both cases the cloud effect increases with increasing wavelength. However, the wavelength dependence of the enhancement of actinic flux in the cloud gap is more pronounced than that measured for the reduction in the shadow of the cloud. A very small wavelength dependence appears in the ratio of the spectrum close to the clear-sky case. 


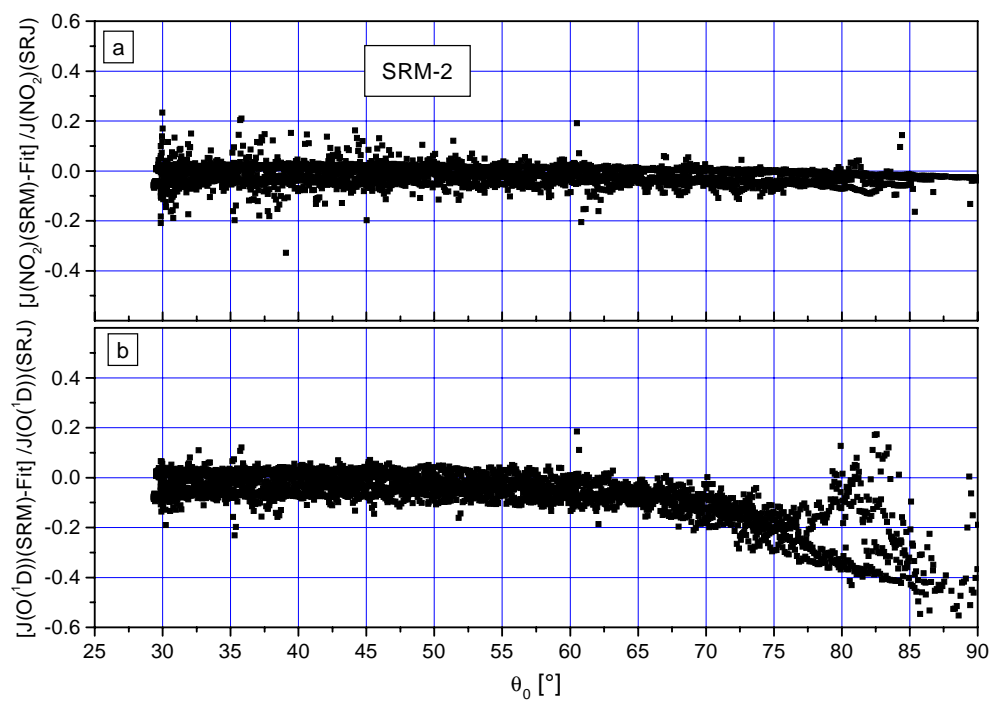

Fig. 9. Relative deviation of the data of (a) $J\left(\mathrm{NO}_{2}\right)$ and (b) $J\left(\mathrm{O}\left({ }^{1} \mathrm{D}\right)\right)$ measured with the SRM (SRM-2) from the linear best-fit lines shown in Fig. 8 as a function of solar zenith angle.

Wavelength-dependent effects of broken clouds on the actinic flux of the same order as shown in this chapter are also found in two-dimensional model simulations with partial cloud cover (Eckstein, 2001). Frederick and Erlick (1997) also observed an increasing reduction of the transmission of irradiance through clouds with increasing wavelength.

The strong decline in the ratios shown in Fig. 11 with decreasing wavelength $(\lambda<320 \mathrm{~nm})$ occurs for two reasons. First, the cloudy and the clear sky spectra are measured at different ozone column values. Second, the multiple scattering in and between the clouds leads to an increase in the light path of up to a factor of 10 (Erle et al., 1995), leading to much stronger absorption by ozone.

In searching for the reasons for the wavelength dependence of the effects of partial clouds, consideration of the ratios of the direct and the diffuse part of the actinic flux is important. The main effect of clouds is the conversion of direct radiation to diffuse radiation due to scattering. In the case of broken clouds, direct radiation, which is scattered at the edge of one cloud, reaches the neighboring cloud and is scattered again, which leads to a tunneling effect between the clouds, increasing the diffuse radiation below the clouds. At a point on the ground where the direct radiation arrives through a cloud gap, additional diffuse radiation is observed compared to the clear sky case, resulting in a higher actinic flux. With increasing wavelength the diffuse part of the actinic flux decreases while the direct radiation increases. Therefore, at longer wavelengths relatively more direct radiation is converted to diffuse radiation below the cloud, leading to the observed wavelength dependence for the enhancement. The same effect leads to the wavelength dependence in the reduced spectra in the shadow of a cloud. Here no direct radiation reaches the ground, because it is scattered at the cloud edge.

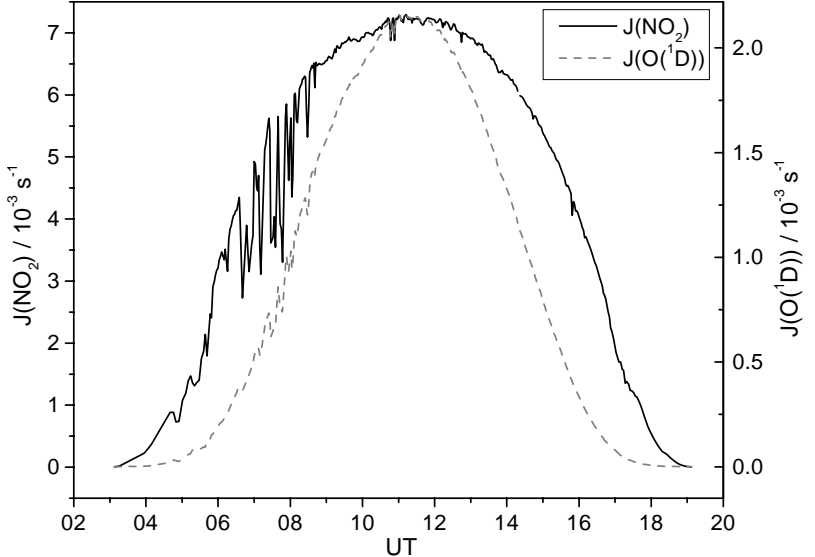

Fig. 10. Photolysis frequencies $J\left(\mathrm{O}\left({ }^{1} \mathrm{D}\right)\right)$ and $J\left(\mathrm{NO}_{2}\right)$ measured with the SRM on 9 August 1998 during the field campaign BERLIOZ in Berlin on the roof of the Charite building. Partial cloud cover in the time from 05:00 to 09:00 UT leads to reductions and enhancements in the photolysis frequencies, whereas the effect is more pronounced in $J\left(\mathrm{NO}_{2}\right)$.

\section{Actinic flux in clouds, experiment on a tower}

The novel feature of the new spectroradiometer represented here, namely to be able to measure at three points simultaneously, was used to analyze the actinic flux within clouds. The instrument was deployed on a tower (height $107 \mathrm{~m}$ ) located on a hill in the Hunsrück region (Germany). The spectroradiometer itself was located in a room in the tower at a height of $60 \mathrm{~m}$. One collector, with a $65 \mathrm{~m}$ fiber, was positioned on top of the tower $(107 \mathrm{~m})$, the second, with a $22 \mathrm{~m}$ fiber, on a platform in the middle of the tower $(68 \mathrm{~m})$ and the third, with a $70 \mathrm{~m}$ fiber, $4 \mathrm{~m}$ above the ground at the bottom of the 

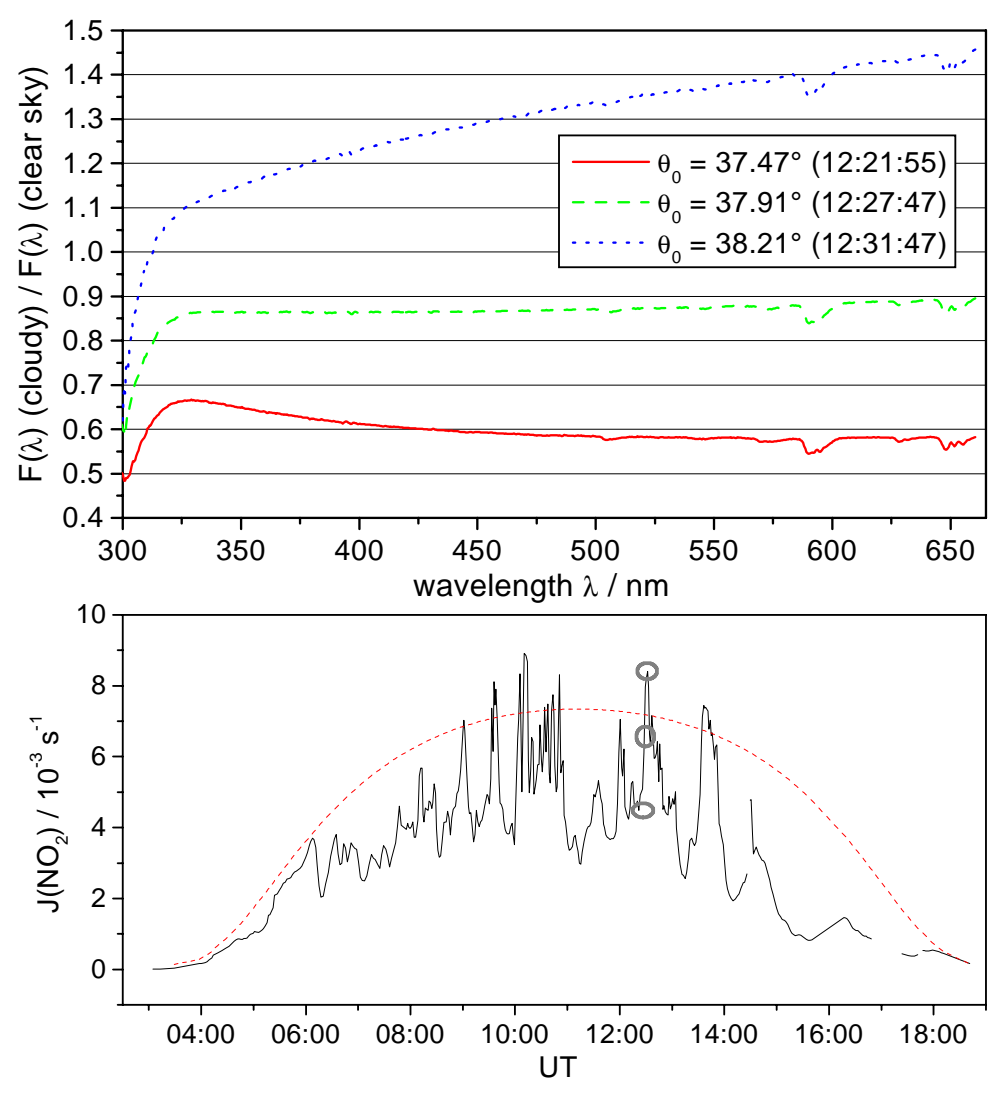

Fig. 11. Deviation of spectra measured during partial cloud cover in relation to clear-sky spectra. The times of the chosen spectra are marked in the photolysis frequency $J\left(\mathrm{NO}_{2}\right)$ in the lower panel. The dashed line in the lower panel is the parameterized clear sky $J\left(\mathrm{NO}_{2}\right)$. In the upper panel, the dotted line corresponds to a point at a local maximum above the clear sky value, the dashed line corresponds to a point near the clear-sky case and the full line corresponds to a local minimum value.

tower. Results are presented for a day where the tower was totally enclosed in clouds that extended to the ground, and thick cloud layers were above the tower. Two wavelength intervals were selected for integration, one interval at short wavelengths and a second interval at longer wavelengths, to check for wavelength dependences. The first interval chosen covered the wavelength range $320-340 \mathrm{~nm}$ in order to exclude the UV-B, which has a strong dependence on the ozone column, thus complicating the cloud effects. The second interval was $605-625 \mathrm{~nm}$, which is free of strong absorption lines. The attenuation $Q_{\text {ext }}$ in the cloud between the collectors is calculated from

$Q_{\text {ext }}(\mathrm{t}-\mathrm{x})=1-\frac{\mathrm{F}_{\mathrm{x}}}{\mathrm{F}_{\mathrm{t}}}$

where $F_{\mathrm{t}}$ is the actinic flux at the top of the tower and $F_{x}$ represents the actinic flux at $68 \mathrm{~m}\left(F_{\mathrm{m}}\right)$ or at the bottom of the tower $\left(F_{\mathrm{b}}\right) . \quad Q_{\text {ext }}(\mathrm{t}-\mathrm{m})$ and $Q_{\text {ext }}(\mathrm{t}-\mathrm{b})$ denote the attenuation between the top and the middle and between the top and the bottom of the tower, respectively. The diurnal variation in both quantities is shown in Fig. 12 for the wavelength integral $605-625 \mathrm{~nm}$, as measured on 14 March 2000. The extinction of the short wavelength interval is omitted as it shows closely similar features. The attenuation $Q_{\text {ext }}$ shows a variation during the day which is more pronounced in $Q_{\text {ext }}(\mathrm{t}-\mathrm{b})$ than in $Q_{\text {ext }}(\mathrm{t}-\mathrm{m})$.

This difference is caused by varying cloud optical thickness, and such fluctuations are larger between the ground and the middle than between the middle and the top of the tower. In addition to the actinic flux spectroradiometer a Fast Scattering Spectrometer Probe (FSSP) was deployed on the middle platform $(68 \mathrm{~m})$ to measure the particle size distribution and the liquid water content of the cloud. Normally the FSSP is an airborne instrument, where the air flowing through a tube is measured. In this experiment a fan was used to suck the air through the measurement tube, reaching air velocities of $50 \mathrm{~m} \mathrm{~s}^{-1}$. In the upper panel of Fig. 12 the measured liquid water content of the clouds is also displayed. Remarkably, the attenuation $Q_{\text {ext }}$ for both distances shows a strong positive correlation with the liquid water content, a relation often used for modelling radiative effects of clouds. $Q_{\text {ext }}(\mathrm{t}-\mathrm{m})$ varies between 0.15 and 0.34 , yielding an attenuation per meter of 0.37 to $0.83 \% \mathrm{~m}^{-1} ; Q_{\text {ext }}(\mathrm{t}-\mathrm{b})$ varies between 0.19 and 0.66 , which results in an attenuation 

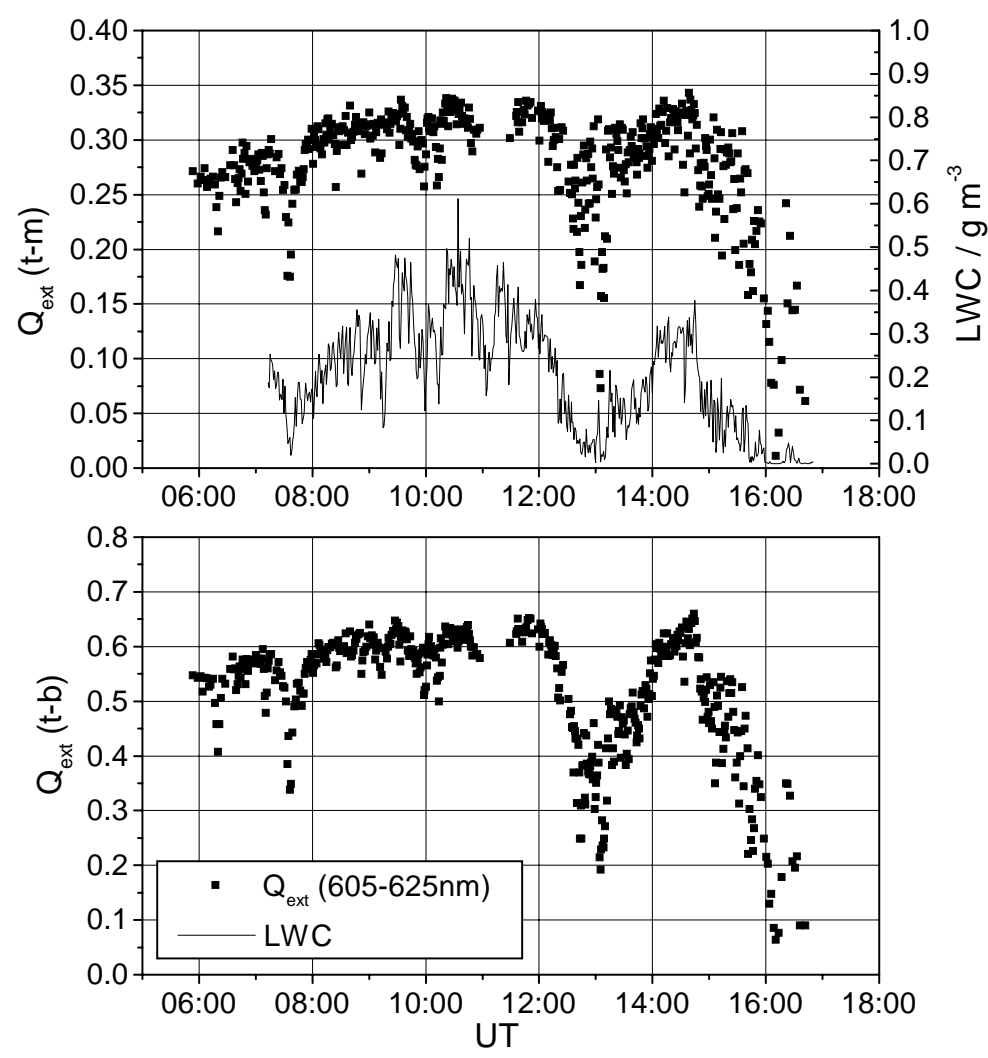

Fig. 12. Attenuation of the actinic flux in the cloud. $Q_{\text {ext }}(\mathrm{t}-\mathrm{m})$ is the reduction of the actinic flux from the top to the middle of tower $(39 \mathrm{~m})$ calculated from $Q_{\text {ext }}(\mathrm{t}-\mathrm{m})=1-\frac{\mathrm{F}_{\mathrm{m}}}{\mathrm{F}_{\mathrm{t}}} ; Q_{\text {ext }}(\mathrm{t}-\mathrm{b})$ is the analogous reduction between the top and the bottom of the tower. The solid line in the upper panel is the liquid water content (LWC) of the cloud measured at a height of $68 \mathrm{~m}$.

of 0.18 to $0.64 \% \mathrm{~m}^{-1}$. These results imply that the actinic flux attenuation per meter was smaller lower down the tower, which would be expected, since the liquid water content, as well as the particle size in a cloud, increases with increasing height.

\section{Conclusions}

A new actinic flux spectroradiometer has been developed, suitable for measurement of most atmospheric photolysis frequencies during field campaigns. The option of measuring spectra from three collectors simultaneously offers the capability to measure simultaneously at three different heights and study, for example the actinic flux in and above clouds.

The instrument is suitable for studying actinic flux, under different cloud conditions, owing to fast and simultaneous measurement of spectra by using a fixed grating imaging spectrograph. The accuracy of the new instrument $( \pm 5 \%$ for $\lambda>330 \mathrm{~nm}$ ) is comparable with existing actinic flux spectroradiometers (Hofzumahaus et al., 1999; Shetter and Müller, 1999). At shorter wavelengths the uncertainty is greater, mainly because of the higher spectrometer stray-light contri- bution to the signal. However, in comparison measurements the SRM showed a very good agreement, in spectra as well as in photolysis frequencies, with the actinic flux spectroradiometer of the Institute of Atmospheric Chemistry of the Forschungszentrum Jülich, which already showed good results in international comparisons.

The advantages of the SRM compared to the other instruments are two-fold. First, the wavelength range 300-660 nm is large, so that nearly every photolysis frequency relevant for atmospheric chemistry can be calculated. Second, in contrast to the existing scanning double monochromator instruments the SRM is fast enough for measuring fast changing partial cloud covering.

The wavelength range of the SRM can be enlarged up to $750 \mathrm{~nm}$, using a suitable filter which reduces just the red light. Furthermore the total blocking of the infra-red radiation could reduce the spectrometer stray-light and therefore improve the accuracy in the UV-B range.

The new $4 \pi$-spectroradiometer measured continuously spectra during the field campaign BERLIOZ. With these actinic flux spectra a large range of photolysis frequencies was calculated, whereas measurements of $J\left(\mathrm{NO}_{2}\right)$ and $J\left(\mathrm{O}\left({ }^{1} \mathrm{D}\right)\right)$ only where shown in this paper. Comparisons for clear sky 
conditions with spectra from $\delta$-4-stream radiative transfer simulations showed very good agreement, with deviations of the calculated spectra from the measurements in the range $\pm 10 \%$ (Früh et al., 2001; Junkermann et al., 2002). The wavelength dependent effects of scattered clouds were also studied. Enhancement of the actinic flux in the cloud gaps was observed, where direct radiation reached the ground, and reduction in actinic flux was observed in the shadow of the clouds. Both effects showed a spectral dependence and were more pronounced with increasing wavelength. A second project comprised measurements made on a tower located on a hill in the Hunsrück region (Germany). The three collectors were deployed in three different heights on the tower to analyze the actinic flux in and above the clouds. The attenuation of the actinic flux in the cloud was correlated with the liquid water content of the cloud. The actinic flux attenuation in the cloud was in the range $0.18-0.83 \% \mathrm{~m}^{-1}$, depending on the optical thickness of the cloud. As expected, a sizeable spectral dependence of the attenuation in the cloud was not observed.

For future measurements the instrument will be modified to reduce the uncertainty in the UV-B range. A new spectroradiometer operating on the same principle for airborne measurements will be developed at the Institut for Tropospheric Research in Leipzig (Germany).

Acknowledgements. This research was supported by the German Federal Ministry for Education, Science, Research and Technology (BMBF), grant TFS-LT3-B.1. We wish to thank A. Hofzumahaus, A. Kraus and B. Bohn for providing the data of the SRJ, and for the possibility and help to carry out the measurement comparisons.

\section{References}

Bahe, F., Marx, W., Schurath, U., and Röth, E.: Determination of the absolute photolysis rate of ozone by sunlight, $\mathrm{O}_{3}+h v \rightarrow \mathrm{O}\left({ }^{1} \mathrm{D}\right)+\mathrm{O}_{2}\left({ }^{1} \Delta_{\mathrm{g}}\right)$, at ground level, Atmos. Env., 13, 1515-1522, 1979.

Barai, S. and Stedman, D.: Actinometric measurement of $\mathrm{J}\left[\mathrm{O}_{3} \rightarrow \mathrm{O}\left({ }^{1} \mathrm{D}\right)\right]$ using a luminol detector, Geophys. Res. Lett., 19, 2047-2050, 1992.

Brauers, T. and Hofzumahaus, A.: Latitudinal variation of measured $\mathrm{NO}_{2}$ photolysis frequencies over the atlantic ocean between $50^{\circ} \mathrm{N}$ and $30^{\circ} \mathrm{S}$, J. Atmos. Chem., 15, 269-282, 1992.

Crawford, J., Davis, D., Chen, G., Shetter, R., Müller, M., Barrick, J., and Olson, J.: An assessment of cloud effects on photolysis rate coefficients: Comparison of experimental and theoretical values, J. Geophys. Res., 104, 5725-5734, 1999.

DeMore, W., Sander, S., Golden, D., Hampson, R., Kurylo, M., Howard, C., Ravishankara, A., Kolb, C., and Molina, M.: Chemical kinetics and photochemical data for use in stratospheric modeling, evaluation number 12, JPL Publication 97-4, California Institute of Technology, Jet Propulsion Laboratory, Pasadena, California, 1997.

Dickerson, R., Stedman, D., and Delany, A.: Direct measurement of ozone and nitrogen dioxide photolysis rates in the troposphere, J. Geophys. Res., 87, 4933-4946, 1982.
Eckstein, E.: Entwicklung eines Spektralradiometers zur Bestimmung von aktinischer Strahlung und Photolysefrequenzen in bewölkter Atmosphäre, Ph.D. thesis, Johannes GutenbergUniversität Mainz, http://ArchiMeD.uni-mainz.de/pub/2002/ 0056, 2001.

Erle, F., Pfeilsticker, K., and Platt, U.: On the influence of tropospheric clouds on zenith-scattered-light measurement of stratospheric species, Geophys. Res. Lett., 22, 2725-2728, 1995.

Frederick, J. and Erlick, C.: The attenuation of sunlight by highlatitude clouds: Spectral dependence and its physical mechanisms, J. Atmos. Sci., 54, 2813-2819, 1997.

Früh, B., Trautmann, T., Wendisch, M., and Keil, A.: Comparison of observed and simulated $\mathrm{NO}_{2}$ photodissociation frequencies in a cloudless atmosphere and in continental boundary layer clouds, J. Geophys. Res., 105, 9843-9857, 2000.

Früh, B., Eckstein, E., Trautmann, T., Wendisch, M., Fiebig, M., and Feister, U.: Ground-based measured and calculated spectra of actinic flux density and downward UV irradiance in cloudless conditions and their sensitivity to aerosol microphysical properties, J. Geophys. Res., 108, D16, 4509, 2003.

Harrison, L., Beauharnois, M., Berndt, J., and Kiedron, P.: The rotating shadowband spectroradiometer (rss) at sgp, Geophys. Res. Lett., 26, 1715-1718, 1999.

Heismann, B.: Eine CCD-Kamera zur Messung atmosphärischer Spurenstoffe, Ph.D. thesis, Ruprecht-Karls-Universität Heidelberg, 1996.

Hofzumahaus, A., Kraus, A., and Müller, M.: Solar actinic flux spectroradiometry: A technique for measuring photolysis frequency in the atmosphere, Appl. Opt., 21, 4443-4460, 1999.

Junkermann, W., Platt, U., and Volz-Thomas, A.: A photoelectric detector for the measurement of photolysis frequencies of ozone and other atmospheric molecules, J. Atmos. Chem., 8, 203-227, 1989.

Junkermann, W., Brühl, C., Perner, D., Eckstein, E., Trautmann, T., Früh, B., Dlugi, R., Gori, T., Ruggaber, A., Reuder, J., Zelger, M., Hofzumahaus, A., Kraus, A., Rohrer, F., Brüning, D., Moortgat, G., Horowitz, A., and Tadic, J.: Actinic radiation and photolysis processes in the lower troposphere: Effect of clouds and aerosols, J. Atmos. Chem., 42, 413-441, 2002.

Kelley, P., Dickerson, R., Luke, W., and Kok, G.: Rate of $\mathrm{NO}_{2}$ photolysis from the surface to $7.6 \mathrm{~km}$ altitude in clear-sky and clouds, Geophys. Res. Lett., 22, 2621-2624, 1995.

Kylling, A., Abold, A., and Seckmeyer, G.: Transmittance of a cloud is wavelength-dependent in the UV-range: Physical interpretation, Geophys. Res. Lett., 24, 397-400, 1997.

Liao, H., Yung, Y. L., and Seinfeld, J. H.: Effect of aerosols on tropospheric photolysis rates in clear and cloudy atmospheres, J. Geophys. Res., 104, 23 697-23 707, 1999.

Madronich, S.: Intercomparison of $\mathrm{NO}_{2}$ photodissociation and U.V. radiometer measurements, Atmos. Env., 21, 569-578, 1987.

Matthijsen, J., Suhre, K., Rosset, R., Eisele, F. L., III, R. L. M., and Tanner, D. J.: Photodissociation and UV radiative transfer in a cloudy atmosphere: Modeling and measurements, J. Geophys. Res., 103, 16665-16676, 1998.

McClatchey, R., Fenn, R., Selby, J., Volz, F., and Garing, J.: Optical properties of the atmosphere AFCRL-71-0279, Environmental Research Paper, 1971.

Merienne, M., Jenouvrier, A., and Coquart, B.: The $\mathrm{NO}_{2}$ absorption spectrum. 1. absorption cross-sections at ambient temperature in 
the 300-500 nm region, J. Atmos. Chem., 20, 281-297, 1995.

Parrish, D., Murphy, P., Albritton, D., and Fehsenfeld, F.: The measurement of the photodissociation rate of $\mathrm{NO}_{2}$ in the atmosphere, Atmos. Env., 32, 2429-2441, 1983.

Reuder, J. and Schwander, H.: Aerosol effects on UV radiation in nonurban regions, J. Geophys. Res., 104, 4065-4077, 1999.

Ruggaber, A., Dlugi, R., and Nakajima, T.: Modelling radiation quantities and photolysis frequencies in the troposphere, J. Atmos. Chem., 18, 171-210, 1994.

Shetter, R. and Müller, M.: Photolysis frequency measurements using actinic flux spectroradiometry during PEM-Tropics mission: Instrumentation description and some results, J. Geophys. Res., 104, 5647-5661, 1999.

Shetter, R., McDaniel, A., Cantrell, C., Madronich, S., and Calvert, J. G.: Actinometer and eppley radiometer measurements of the $\mathrm{NO}_{2}$ photolysis rate coefficient during the Mauna Loa Observatory Photochemistry Experiment, J. Geophys. Res., 97, 10349$10359,1992$.
Talukdar, R., Longfellow, C., Gilles, M., and Ravishankara, A.: Quantum yields of $\mathrm{O}\left({ }^{1} \mathrm{D}\right)$ in the photolysis of ozone between 289 and $329 \mathrm{~nm}$ as a function of temperature, Geophys. Res. Lett., 25, 143-146, 1998.

van Weele, M. and Duynkerke, P.: Effects of clouds on the photodissociation of $\mathrm{NO}_{2}$ : Observations and modelling, J. Atmos. Chem., 16, 231-255, 1993.

van Weele, M., de Arellano, J. V.-G., and Kuik, F.: Combined measurements of UV-A actinic flux, UV-A irradiance and global radiation in relation to photodissociation rates, Tellus, 47B, 353-364, 1995. 